Article

\title{
Gas Sensing with Iridium Oxide Nanoparticle Decorated Carbon Nanotubes
}

\author{
Juan Casanova-Cháfer ${ }^{1}$ (D), Eric Navarrete ${ }^{1}$ (D), Xavier Noirfalise ${ }^{2}$, Polona Umek ${ }^{3}$, \\ Carla Bittencourt ${ }^{4}$ and Eduard Llobet ${ }^{1, *(D)}$ \\ 1 MINOS-EMaS, Universitat Rovira i Virgili, 43007 Tarragona, Spain; juan.casanova@urv.cat (J.C.-C.); \\ eric.navarrete@urv.cat (E.N.) \\ 2 Materia Nova, 7000 Mons, Belgium; xavier.noirfalise@umons.ac.be \\ 3 Jožef Stefan Institute, 10000 Ljubljana, Slovenia; polona.umek@ijs.si \\ 4 ChIPS, University of Mons, 7000 Mons, Belgium; carla.bittencourt@umons.ac.be \\ * Correspondence: eduard.1lobet@urv.cat; Tel.: +34-997-558-502
}

Received: 21 November 2018; Accepted: 25 December 2018; Published: 31 December 2018

check for updates

\begin{abstract}
The properties of multi-wall carbon nanotubes decorated with iridium oxide nanoparticles ( $\mathrm{IrO}_{\mathrm{x}}-\mathrm{MWCNTs}$ ) are studied to detect harmful gases such as nitrogen dioxide and ammonia. $\operatorname{IrO}_{\mathrm{x}}$ nanoparticles were synthetized using a two-step method, based on a hydrolysis and acid condensation growth mechanism. The metal oxide nanoparticles obtained were employed for decorating the sidewalls of carbon nanotubes. Iridium-oxide nanoparticle decorated carbon nanotube material showed higher and more stable responses towards $\mathrm{NH}_{3}$ and $\mathrm{NO}_{2}$ than bare carbon nanotubes under different experimental conditions, establishing the optimal operating temperatures and estimating the limits of detection and quantification. Furthermore, the nanomaterials employed were studied using different morphological and compositional characterization techniques and a gas sensing mechanism is proposed.
\end{abstract}

Keywords: iridium oxide; carbon nanotubes; chemoresistive gas sensor; metal nanoparticles; relative humidity effect

\section{Introduction}

Chemical sensors employing carbon nanomaterials, like carbon nanotubes and graphene, have attracted great research interest. Specifically, carbon nanotubes have been extensively employed in gas sensing applications due to their suitable electronic, physical, and chemical properties, such as nanometer-size, high carrier mobility, and surface area to volume ratio [1]. Additionally, by functionalizing the sidewalls of multi-wall carbon nanotubes (MWCNT), some sensing properties can be enhanced, such as reproducibility, selectivity, and sensitivity [2]. Different options have been widely used to improve gas sensing performance, such as grafting functional groups onto the carbon nanotubes (CNT) surface [3] or decorating them with metal or metal oxide nanoparticles [4]. Nanoparticles present some advantages like high surface area, control over the local environment, and improved mass transport that cannot be achieved at bulk level [5].

Even though many papers have been published on the attachment of metal or metal oxide nanoparticles on carbon nanotube sidewalls [4], to the best of our knowledge this is the first time that the decoration of carbon nanotubes with iridium oxide nanoparticles in chemoresistive gas sensing is studied. For that reason, this paper reports the improvements obtained by loading MWCNTs with $\mathrm{IrO}_{\mathrm{x}}$ nanoparticles.

Iridium oxide has been reported for electrochemical sensing and catalyst applications, especially for water splitting at low or moderate temperatures [6] due to its ideal properties such as high 
catalytic activity, stability, and selectivity under specific reaction conditions [5]. In addition, $\mathrm{IrO}_{\mathrm{x}}$ was employed in biosensing applications $[7,8]$ and as a $\mathrm{pH}$ sensor $[9,10]$. Iridium oxide behaves as a p-type semiconductor with medium band gap energy $(3.12 \mathrm{eV})$ and charge carrier concentration of $4.2 \times 10^{21} \mathrm{~cm}^{-3}$ [11]. In addition, iridium, has been employed to modify different metal oxides for gas sensing. Even if metal oxides are loaded with iridium metal, it appears in the form of iridium oxide nanoparticles at the high operating temperatures of metal oxide gas sensors. Iridium oxide has been reported to catalyze gallium oxide for detecting ethanol and propane at $600{ }^{\circ} \mathrm{C}$ [12], combined to tungsten oxide for detecting ethanol [13], added to titanium oxide films for detecting oxygen [14], or employed in combination with tin oxide in an attempt to diminish moisture cross-sensitivity in the detection of carbon monoxide [15].

As already reported [16], the presence of oxygenated defects and functional groups (e.g., carboxylic acid) on the sidewalls of MWCNTs helps in achieving a stable grafting of metal or metal oxide nanoparticles to carbon nanotubes and enables an efficient charge carrier transfer between them. Therefore, this approach was also employed here for the grafting $\mathrm{IrO}_{x}$ nanoparticles onto carbon nanotubes in view of developing simple, low cost chemoresistive gas sensors.

The hybrid nanomaterial and gas sensors were characterized employing different techniques such as Raman spectroscopy, transmission electron microscopy (TEM), scanning electron microscopy (SEM), and X-ray photoelectron spectroscopy (XPS) to elucidate morphology and chemical composition. The resistance changes during the exposure to different contaminant gases under different experimental conditions were measured.

While it is well-known that carbon nanomaterials show remarkable sensitivity to nitrogen dioxide, the performance of metal or metal oxide NP decorated CNTs in the detection of ammonia vapors remains rather poor. Probably this is due to the significantly weaker affinity between $\mathrm{NH}_{3}$ and carbon nanotubes and its associated poor charge transfer efficiency [17]. However, the capability of $\mathrm{IrO}_{x}$ to detect $\mathrm{NH}_{3}$ has been reported [18] and for that reason, in this paper we explore the possibility of employing $\mathrm{IrO}_{\mathrm{x}}-\mathrm{MWCNTs}$ as gas-sensitive material for detecting $\mathrm{NO}_{2}$ and $\mathrm{NH}_{3}$.

\section{Materials and Methods}

\subsection{Material Synthesis}

The synthesis of iridium oxide $\left(\mathrm{IrO}_{x}\right)$ nanoparticles was achieved following the method proposed by Zhao [19], in which a solution of iridium oxide nanoparticles is prepared via a two-step process (Equation (1)). The first step consists of the preparation of $2 \mathrm{mM}$ dissolution using potassium hexachloroiridate (IV) $\left(\mathrm{K}_{2} \mathrm{IrCl}_{6}\right)$ in $100 \mathrm{~mL}$ of distilled water. Then, $\mathrm{pH}$ was adjusted to 13 employing sodium hydroxide $(\mathrm{NaOH})$ diluted in distilled water and the product was heated to $90{ }^{\circ} \mathrm{C}$ during $30 \mathrm{~min}$ to ensure the total hydrolysis of $\mathrm{K}_{2} \mathrm{IrCl}_{6}$, breaking the $\mathrm{Ir}-\mathrm{Cl}$ bonds and creating the complex $\left[\operatorname{Ir}(\mathrm{OH})_{6}\right]^{-2}$. This resulted in a color change of the dissolution from red-brown $\left(\mathrm{K}_{2} \mathrm{IrCl}_{6}\right)$ to yellow $\left(\left[\operatorname{Ir}(\mathrm{OH})_{6}\right]^{-2}\right)$ (see Equation (1)).

An acid condensation process was conducted in the second step, in which a $3 \mathrm{M}$ nitric acid $\left(\mathrm{HNO}_{3}\right)$ dissolution was employed to decrease the $\mathrm{pH}$ to 1 under vigorous stirring during $90 \mathrm{~min}$ in order to avoid the formation of precipitates. In this step, the $\left(\left[\operatorname{Ir}(\mathrm{OH})_{6}\right]^{-2}\right)$ complex forms ligand-free $\operatorname{IrO}_{x}$ nanoparticles dispersed in water, with their characteristic deep blue color (see Figure S1 Supplementary Materials) due to the protonation and condensation of $\left(\left[\operatorname{Ir}(\mathrm{OH})_{6}\right]^{-2}\right)$. Once the iridium nanoparticles are formed, it is important to store the dissolution at $2{ }^{\circ} \mathrm{C}$ to avoid the formation of precipitates.

$$
\left[\mathrm{IrCl}_{6}\right]^{-2} \stackrel{\mathrm{OH}^{-}}{\rightarrow}\left[\mathrm{Ir}(\mathrm{OH})_{6}\right]^{-2} \stackrel{\mathrm{H}^{+}}{\rightarrow} \mathrm{IrO}_{\mathrm{x}}+\mathrm{nH}_{2} \mathrm{O}
$$

Once the metal oxide nanoparticles had been obtained, the surface of MWCNTs was decorated by attaching the $\mathrm{IrO}_{x}$ nanoparticles via an impregnation technique. The impregnation technique consists of the dropwise addition of metal nanoparticles to a MWCNTs solution heated at $80^{\circ} \mathrm{C}$ under vigorous 
stirring. Functionalized MWCNTs were purchased from Nanocyl S.A. (Belgium) with carbonyl and carboxyl functional groups grafted to their surface because these MWCNTs had undergone a cold plasma treatment. As already stated, the presence of these functional groups on the carbon nanotubes sidewalls helps attaching the iridium oxide nanoparticles onto their outer wall.

\subsection{Material Characterization}

The nanomaterials obtained were analyzed employing several techniques. For instance, both the crystallinity of carbon nanotubes and the confirmation of the presence of iridium oxide nanoparticles in the hybrid samples were evaluated using Raman Spectroscopy. This analysis was performed using a Raman spectrometer from Renishaw, plc. (Wotton-under-Edge, UK), which was coupled to a confocal Leica DM2500 microscope. The laser employed had a wavelength of $514 \mathrm{~nm}$.

The morphology of the hybrid nanomaterial was studied via scanning electron microscopy (SEM) using a SU8020 Microscope from Hitachi (Tokio, Japan) at an operating voltage of $30 \mathrm{kV}$. In addition, transmission electron microscopy (TEM) using a JEM-1011 from Jeol Ltd. (Tokio, Japan) and high resolution TEM (Jeol 2100, $200 \mathrm{keV}$ ) equipped with an energy-dispersive X-ray spectrometer (EDXS) for elemental analysis were also performed. The specimens for high resolution TEM investigation were ultrasonically dispersed in $\mathrm{MeOH}$ and a drop of dispersion was deposited onto a lacy carbon film supported by a copper grid. Moreover, a drop of the $\mathrm{IrO}_{\mathrm{x}}$ suspension was deposited onto a copper grid and studied by TEM.

The chemical composition of the hybrid sample was studied via X-ray photoelectron spectroscopy (XPS) using a VERSAPROBE PHI 5000 from Physical Electronics Inc. (Chanhassen, MN, USA), equipped with a Monochromatic $\mathrm{Al} \mathrm{K} \alpha \mathrm{X}$-ray. The energy resolution was $0.6 \mathrm{eV}$. For the compensation of built charge during the measurements, a dual beam charge neutralization composed of an electron gun $(\sim 1 \mathrm{eV})$ and an Argon ion gun $(<10 \mathrm{eV})$ was used. All binding energies were calibrated to the $\mathrm{Au}$ $4 \mathrm{f}_{7 / 2}(84.0 \mathrm{eV})$.

\subsection{Sensor Fabrication}

A silicon wafer was oxidized in a tubular furnace during $6 \mathrm{~h}$ at $1100{ }^{\circ} \mathrm{C}$ under continuous flow of dry oxygen. This process results in the growth of a silicon dioxide layer $\left(\mathrm{SiO}_{2}\right)$ on both sides of the wafer. The wafer was diced. In the polished side of a given die, MWCNTs (either pristine or decorated with iridium oxide nanoparticles) were deposited by an airbrush technique, using a shadow mask. On the other side of the die (non-polished), a platinum screen-printed alumina heater was glued employing a thermally conductive epoxy and subsequently bonded to a $20 \times 30 \mathrm{~mm}$ printed circuit board (PCB). Finally, two wire contacts were made on the surface of the sensor using a silver epoxy paste (Ag component metallization, Heraeus). The sensor layout was designed and implemented in order to be placed in a Teflon airtight chamber, which was connected to a computer controlled gas mixture and delivery system that employed mass-flow controllers from Bronkhorst High-Tech B.V. (Ruurlo, The Netherlands) and electro-valves (see Figure S2 Supplementary Materials).

\subsection{Gas Sensing Studies}

Calibrated gas cylinders of the different gases/vapors tested were employed diluted in a balance of synthetic dry air (Air Premier Purity: 99.995\%). Pure dry air was also used as carrier gas. To achieve the desired analyte concentrations, successive dilutions were done using synthetic dry air. The total flow was adjusted to $100 \mathrm{~mL} / \mathrm{min}$, stabilizing the sensors with synthetic dry air during $1 \mathrm{~h}$ between exposures ( $30 \mathrm{~min})$ to the target gas concentration. Sensor response is defined as $\left(\Delta R / R_{0}\right)$ expressed in percentage, where $\Delta R$ is the resistance change over the 30-min exposure time and $R_{0}$ is the baseline resistance. The time needed for achieving a stable sensor resistance value after a sudden exposure to nitrogen dioxide or ammonia exceeds one hour. In addition, recovering the initial baseline in dry air, especially after being exposed to nitrogen dioxide, takes a few hours. Therefore, to speed up the characterization process, the exposure and recovery times were arbitrarily set to $30 \mathrm{~min}$ and one hour, 
respectively. This implies that sensor responses reported are pessimistically biased, since allowing for the full stabilization during response and recovery would result in higher resistance changes than those reported. The different species were tested at three different operating temperatures (i.e., room temperature, $100{ }^{\circ} \mathrm{C}$ and $150{ }^{\circ} \mathrm{C}$ ). Moreover, a controlled evaporator and mixer from Bronkhorst High-Tech B.V. (Ruurlo, The Netherlands) was used to humidify gas samples during the measurements, enabling the study of the relative humidity (R.H.) effect on sensor response. Resistance changes of the different gas sensitive films tested were monitored by an Agilent HP 34972A multimeter.

\section{Results}

At first, the morphology and composition of the hybrid gas sensitive nanomaterial was characterized employing Raman spectroscopy, SEM, TEM, and XPS.

\subsection{Material Characterization Results}

Figure 1a shows the Raman spectrum of the hybrid nanomaterial with the well-known bands at $1350 \mathrm{~cm}^{-1}$ (D), $1580 \mathrm{~cm}^{-1}$ (G), $2680 \mathrm{~cm}^{-1}$ (2D), and $2950 \mathrm{~cm}^{-1}$ (2iTO). D and 2D band are related to the presence of defects such as disorder in the $\mathrm{sp}^{2}$ carbon nanostructure, amorphous carbon or carbonaceous impurities, meanwhile $\mathrm{G}$ band represents the in-plane vibrations of $\mathrm{sp}^{2}$ carbon bonds [20]. Taking in consideration the ratio between the intensities of $D$ and $G$ bands (D/G ratio), it was confirmed that the MWCNTs employed here are not highly crystalline. This is due to the presence of defects and oxygenated functional groups attached to the sidewalls of nanotubes resulting from the oxygen plasma treatment. However, the presence of these oxygenated defects plays an essential role in the anchoring process of $\mathrm{IrO}_{x}$ nanoparticles. Besides, the presence of oxygenated species in the surface of MWCNTs enhance their reactivity [16]. In other words, the presence of functional groups (i.e., COOH) contributes to increasing the sensitivity to gas molecules. In addition, Raman measurements revealed the decoration of MWCNTs with $\mathrm{IrO}_{\mathrm{x}}$ (see Figure 1b), because the presence of $\mathrm{IrO}_{\mathrm{x}}$ active modes $\left(\mathrm{E}_{\mathrm{g}}\right.$, $\mathrm{B}_{2 \mathrm{~g}}$, and $\mathrm{A}_{1 \mathrm{~g}}$ ) [21] could be detected.

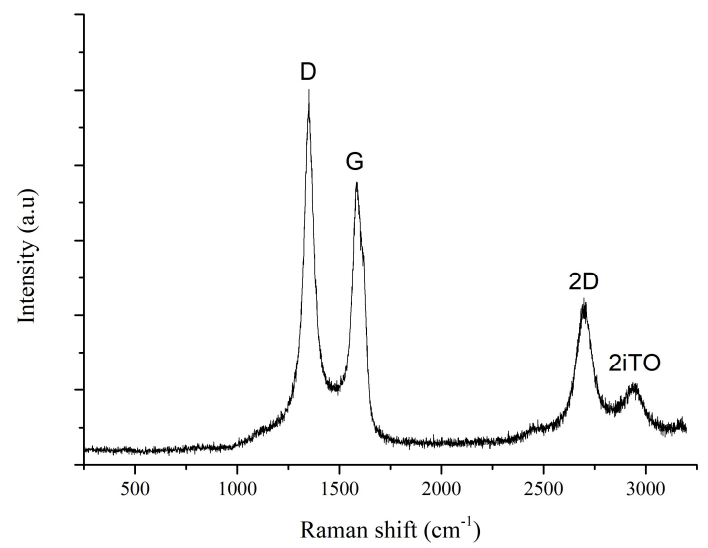

(a)

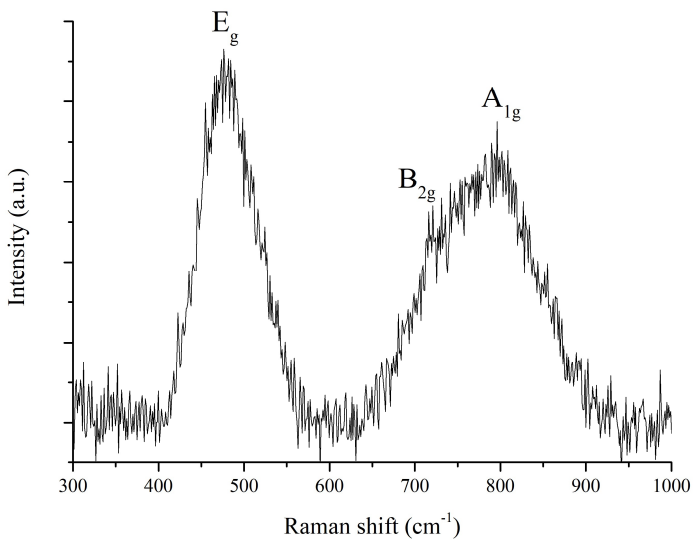

(b)

Figure 1. Typical Raman spectrum of the multi-wall carbon nanotubes (MWCNTs) used (a). Detailed Raman spectrum recorded in the $300-1000 \mathrm{~cm}^{-1}$ region corresponding to peaks attributed to the presence iridium oxide nanoparticles in $\mathrm{IrO}_{\mathrm{x}}-\mathrm{MWCNT}$ samples (b).

SEM analysis shows that the hybrid nanomaterial consists of mats of disordered MWCNTs (Figure 2a). Some white spots appearing in the SEM micrograph (due to charge accumulation) can be attributed to the presence of semiconductor $\mathrm{IrO}_{\mathrm{x}}$ nanoparticles sitting on the rather conductive MWCNTs. The synthesis method produced small nanoparticles, the size of which was $1 \pm 0.3 \mathrm{~nm}$ (see Figure 2a inset). $\mathrm{IrO}_{\mathrm{x}}$ nanoparticles appear as dark spots in TEM micrographs. The presence of $\mathrm{IrO}_{\mathrm{x}}$ nanoparticles was further confirmed by HR-TEM and EDXS analysis (see Figure $2 \mathrm{~b}$ and Figure 
S3 Supplementary Materials). The HR-TEM image also shows that the structure of the MWCNTs is preserved after the plasma and $\mathrm{IrO}_{\mathrm{x}}$ impregnation treatments.

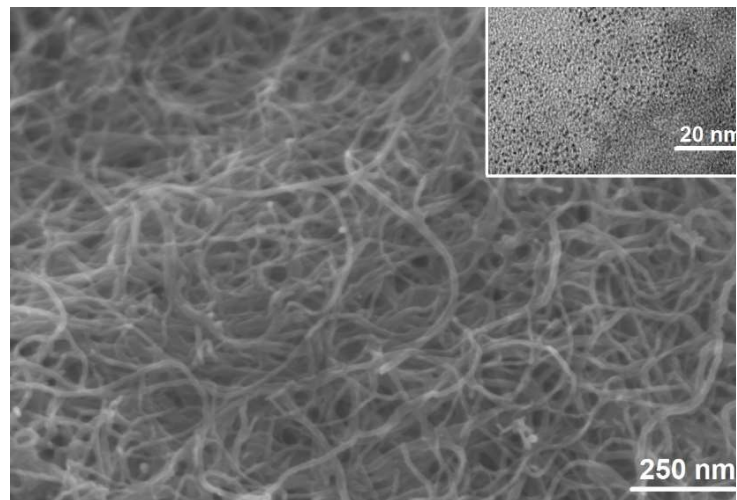

(a)

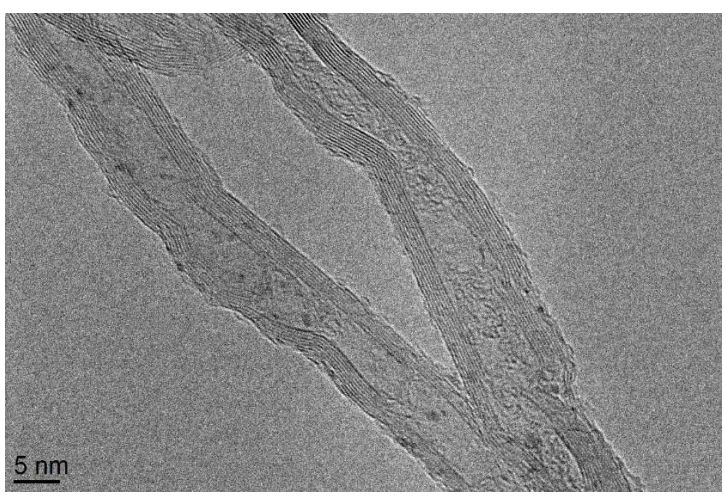

(b)

Figure 2. (a) SEM image showing the morphology of the $\mathrm{IrO}_{\mathrm{x}}-\mathrm{MWCNT}$ sample. $\mathrm{IrO}_{\mathrm{x}}$ nanoparticles (bright spots) can be observed at the MWCNT surface. The inset shows a TEM image of as synthesized iridium oxide nanoparticles (dark spots). (b) HR-TEM image showing MWCNT with $\mathrm{IrO}_{\mathrm{x}}$ nanoparticles (dark spots).

The results of the XPS analysis are presented in Figure 3. The C1s spectrum is reproduced by five components centered at binding energy $284.4 \mathrm{eV}, 285.5 \mathrm{eV}, 287.2 \mathrm{eV}, 288.9 \mathrm{eV}$, and $291.4 \mathrm{eV}$ (Figure 3a). The components at $284.4 \mathrm{eV}$ and $291.0 \mathrm{eV}$ are characteristic of $\mathrm{sp}^{2}$ carbon systems, the first can be associated to photoelectrons emitted from carbon atoms in the carbon nanotube 'graphite-like' walls, while the second reflects the electron energy loss peak due to the collective excitation of $\pi$ electrons, the so-called $\pi$ plasmon [22,23]. The other three components are associated to photoelectrons emitted from carbon atoms at $\mathrm{sp}^{3}$ bonds, oxygen-containing groups such as $\mathrm{C}-\mathrm{O}$ and in carboxylic groups, respectively [24].

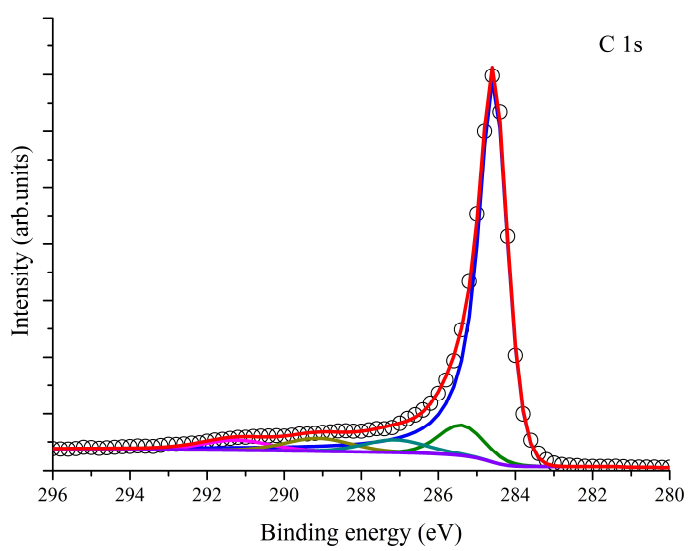

(a)

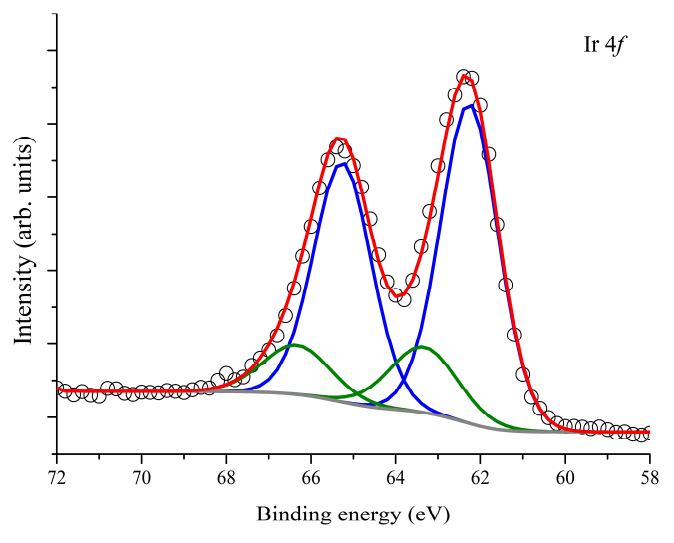

(b)

Figure 3. Deconvolution of the C 1s core level peak for bare MWCNTs (a). Deconvolution of the Ir $4 \mathrm{f}$ core level peak for iridium oxide nanoparticles $(\mathbf{b})$.

Figure 3b shows a typical Ir 4f XPS spectrum recorded on the hybrid nanomaterial and its fitting result. Two doublets of Gaussian-Lorentzian convolution were used to reproduce the experimental data. The spin-orbit doublet binding energy splitting in each doublet was $2.9 \mathrm{eV}$ and the intensity ratio 7:5. The first doublet with components at $62.3 \mathrm{eV}\left(4 \mathrm{f}_{7 / 2}\right)$ and $65.3 \mathrm{eV}\left(4 \mathrm{f}_{5 / 2}\right)$ testifies for the presence of Ir (III) while the second doublet with components centered at $63.4 \mathrm{eV}$ and $66.4 \mathrm{eV}$ the presence of $\operatorname{Ir}(\mathrm{IV})[25,26]$. The fact that Ir presents two oxidation states is favourable for gas sensing, as will be discussed later. 


\subsection{Gas Sensing Results}

The ability of the hybrid nanomaterial developed for detecting different gases was evaluated, showing significant results in the detection of $\mathrm{NH}_{3}$ and $\mathrm{NO}_{2}$ at ppm and ppb levels, respectively. Sensors employing decorated MWCNTs with $\mathrm{IrO}_{\mathrm{x}}$ nanoparticles showed enhanced sensitivity, stability, and reproducibility than those employing bare carbon nanotubes.

$\mathrm{NH}_{3}$ detection was performed by analyzing repeated response and recovery cycles to four concentrations (25, 50,75, and $100 \mathrm{ppm}$, successively), showing an important increase in response (six-fold) for $\mathrm{IrO}_{\mathrm{x}}$ loaded carbon nanotubes, compared to bare carbon nanotube sensors. Moreover, apart from the higher response, $\mathrm{IrO}_{x}-\mathrm{MWCNT}$ presented a better reproducibility and higher stability (see Figure 4a). In addition, the responses were analyzed at three different sensor operating temperatures and $\mathrm{IrO}_{\mathrm{x}}$-decorated MWCNT sensors showed higher ammonia responses than bare MWCNT sensors for any of the operating temperatures studied. The best working conditions were found to be $100{ }^{\circ} \mathrm{C}$, considering the higher intensity of response and sensitivity (slope) achieved at this operating temperature (see Figure $4 \mathrm{~b}$ ). Error bars are standard deviations of responses.

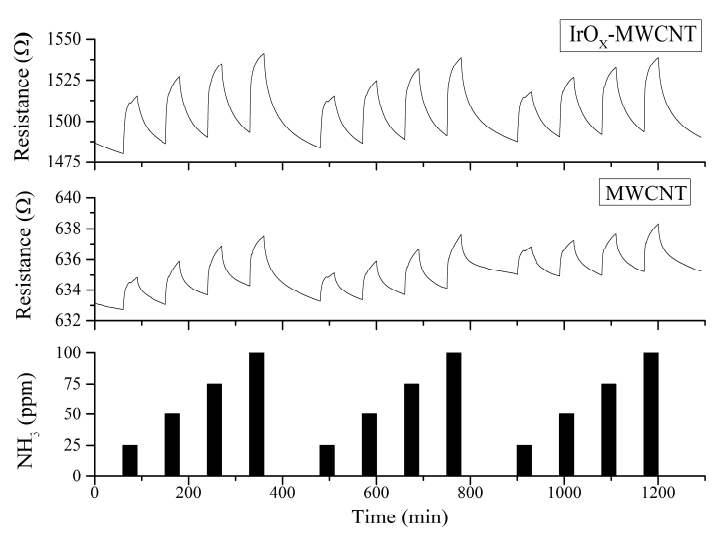

(a)

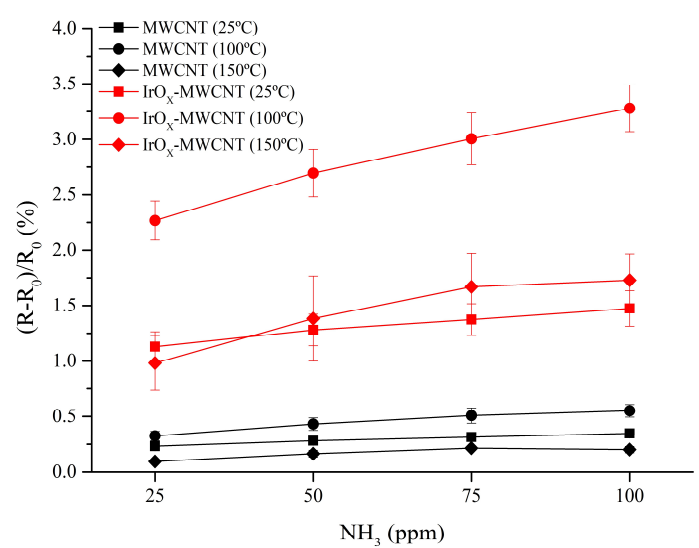

(b)

Figure 4. Typical resistance response obtained when detecting $\mathrm{NH}_{3}$ at a sensor operating temperature of $100{ }^{\circ} \mathrm{C}(\mathbf{a})$. Calibration curves obtained for $\mathrm{NH}_{3}$ at different operating temperatures (b).

The process followed for measuring $\mathrm{NO}_{2}$ was similar to the one employed for $\mathrm{NH}_{3}$. However, in this case four concentrations (see Figure 5a) were analyzed (250, 500, 750, and $1000 \mathrm{ppb}$ ), again for three different operating temperatures. It can be observed that a better responsiveness towards $\mathrm{NO}_{2}$ (two-fold increase) was obtained for MWCNTs loaded with $\mathrm{IrO}_{\mathrm{x}}$ nanoparticles. Taking in consideration the responses obtained under different working conditions, the optimal operating temperature for detecting $\mathrm{NO}_{2}$ was established at $150{ }^{\circ} \mathrm{C}$ (see Figure $5 b$ ).

In addition, cross-sensitivity was evaluated measuring other gases. Some aromatic volatile organic compounds (VOCs), such as benzene and toluene were measured at low concentrations and at different operating temperatures without achieving high sensor responses during their exposure to these compounds. Exposure to ethanol $\left(\mathrm{C}_{2} \mathrm{H}_{6} \mathrm{O}\right)$ vapors did not resulted in significant response either. High concentration (100 ppm) of carbon monoxide (CO) was also tested, yet unsuccessfully. Besides, hydrogen was measured until high concentrations (e.g., $1000 \mathrm{ppm}$ ) resulting in extremely low response. A comparison of the responses obtained for the different gases tested can be observed in Figure 6. This figure reports a sensitivity coefficient that is defined as the ratio between the response measured and concentration tested for any given species. It can be derived that $\mathrm{IrO}_{\mathrm{x}}-\mathrm{MWCNTs}$ are suitable for detecting $\mathrm{NO}_{2}$ and $\mathrm{NH}_{3}$ with small cross-sensitivity from other species. 


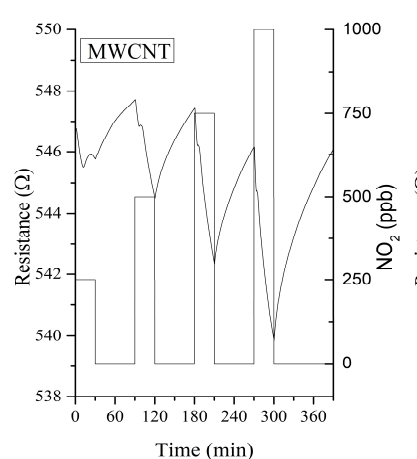

Time (min)

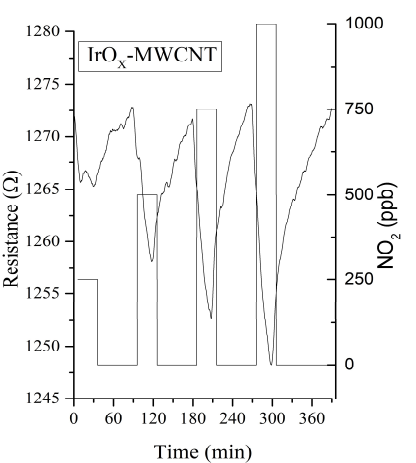

(a)

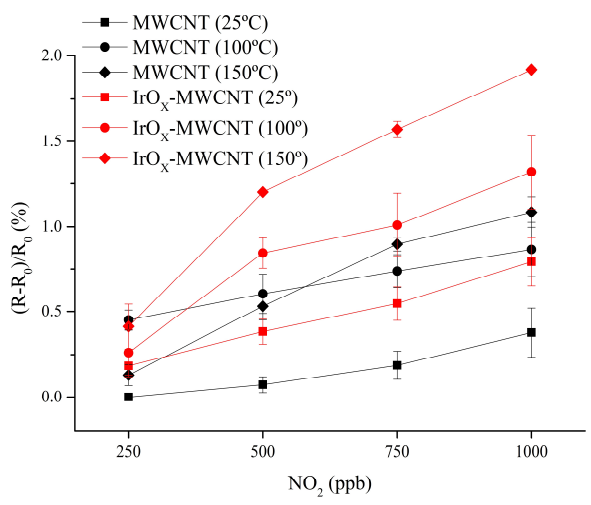

(b)

Figure 5. Typical response and recovery of the resistance signals when the sensors are exposed to different concentrations of $\mathrm{NO}_{2}$ (a). Calibration curves obtained for $\mathrm{NO}_{2}$ for bare carbon nanotubes and $\mathrm{IrO}_{\mathrm{X}}-\mathrm{MWCNT}$ at different operating temperatures under dry conditions. Error bars are standard deviations of responses $(\mathbf{b})$.

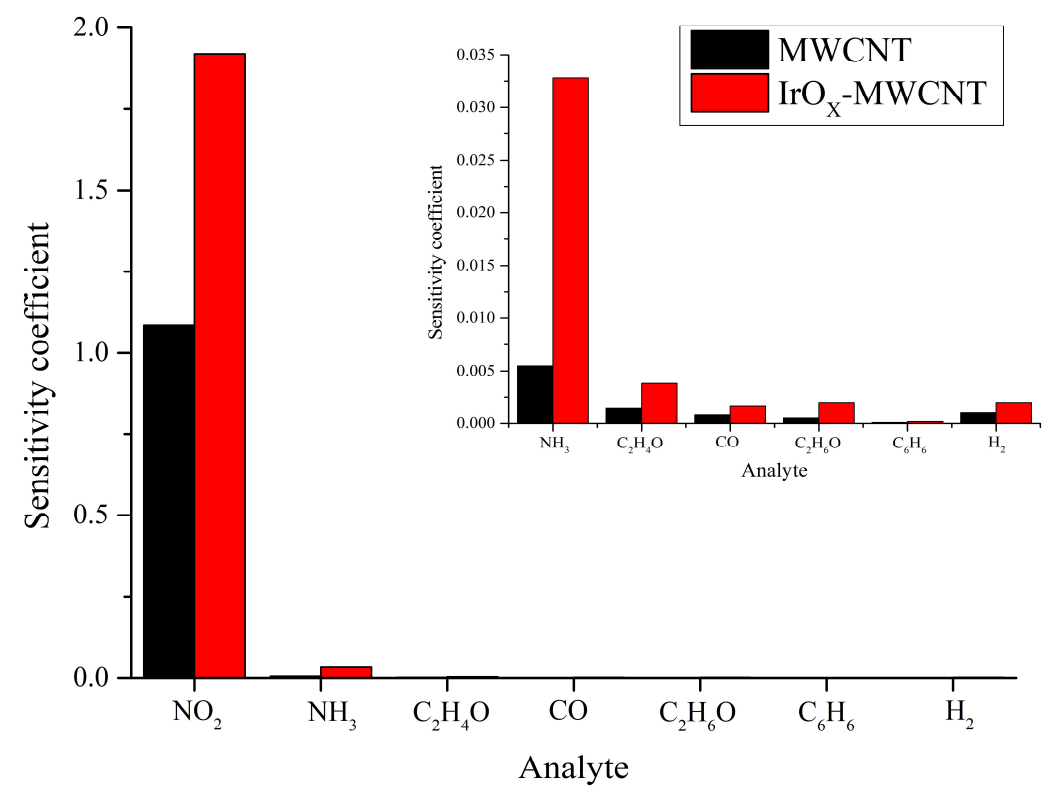

Figure 6. Sensitivity coefficient expressed as response/concentration for the different species tested (the inset is an enlargement showing the coefficients for those gaseous species with lower sensitivity coefficients). The sensitivity coefficients were obtained employing the highest response registered at specific concentrations, which were 1 ppm for $\mathrm{NO}_{2} ; 20$ ppm for $\mathrm{C}_{2} \mathrm{H}_{6} \mathrm{O}$ and $\mathrm{C}_{6} \mathrm{H}_{6} ; 100$ ppm for $\mathrm{CO}$, $\mathrm{C}_{2} \mathrm{H}_{4} \mathrm{O}$ and $\mathrm{NH}_{3}$; and 1000 ppm for $\mathrm{H}_{2}$.

Acetaldehyde $\left(\mathrm{C}_{2} \mathrm{H}_{4} \mathrm{O}\right)$ was also measured, obtaining a non-conclusive response for bare carbon nanotubes. However, decorated MWCNTs with iridium nanoparticles show a fast and saturated response when $\mathrm{C}_{2} \mathrm{H}_{4} \mathrm{O}$ is applied at $100{ }^{\circ} \mathrm{C}$ (Figure S4 Supplementary Materials), even at room temperature. However, an important drift can be observed together with a progressive de-sensitization effect over time, probably due to an irreversible adsorption by the repeated exposure of the gas-sensitive film towards $\mathrm{C}_{2} \mathrm{H}_{4} \mathrm{O}$ at low temperatures.

The humidity effect on gas sensing performance was also analyzed. When the humidity background changes from dry to $50 \%$ R.H., the baseline resistance of $\mathrm{IrO}_{\mathrm{x}}-\mathrm{MWCNTs}$ increases by $3.2 \%$ on average. Once this new baseline under humid conditions was reached and stable, which took about $5 \mathrm{~min}$, ammonia and nitrogen dioxide measurements under humid conditions were performed. Bare carbon nanotubes show an important increase in the response towards nitrogen dioxide and ammonia 
when humidity is present, probably because of transfer of electronic charge from adsorbed water molecules towards carbon nanotubes depletes carbon nanotubes from holes in p-type carbon nanotube mats [27]. In contrast, during their exposure to $\mathrm{NH}_{3}$, the response of $\mathrm{IrO}_{\mathrm{x}}$-decorated MWCNTs remains virtually unaffected by the presence of ambient moisture (see Figure 7). Even that a slight decrease in the response towards $\mathrm{NH}_{3}$ can be observed in Figure 7, this change falls within the range of the measurement uncertainty.
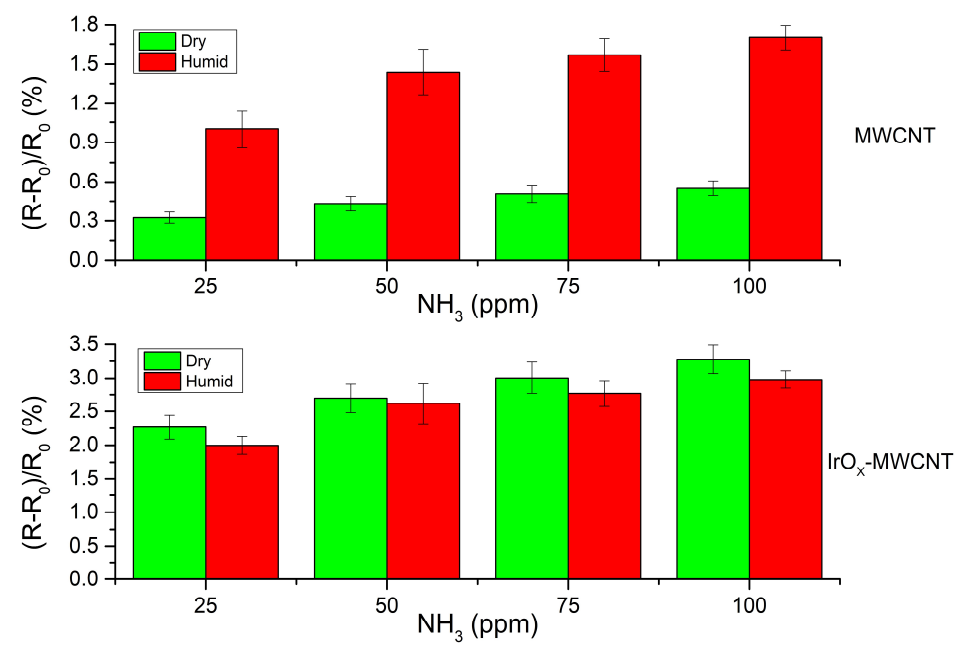

Figure 7. Comparison of the response towards ammonia for bare and $\mathrm{IrO}_{x}$-decorated MWCNTs under dry and humid $\left(50 \%\right.$ R.H.) conditions. Sensors were operated at $100^{\circ} \mathrm{C}$. For bare carbon nanotubes, the response towards ammonia shows a four-fold increase when under humid conditions. $\mathrm{IrO}_{\mathrm{x}}$-MWCNTs present a slightly lower response to ammonia in humid conditions than in dry air.

Similarly, the response to $\mathrm{NO}_{2}$ was evaluated in the presence of ambient moisture ( $50 \%$ R.H.) for a sensor working temperature of $150{ }^{\circ} \mathrm{C}$. Figure 8 shows a high increase in the response towards $\mathrm{NO}_{2}$ of $\mathrm{IrO}_{\mathrm{x}}-\mathrm{MWCNTs}$ when under humid conditions. Figure S5 (Supplementary Materials) shows a typical dynamic response of a sensor for nitrogen dioxide under humid conditions. The possible gas sensing mechanism to explain this effect will be detailed later on, in the discussion section.

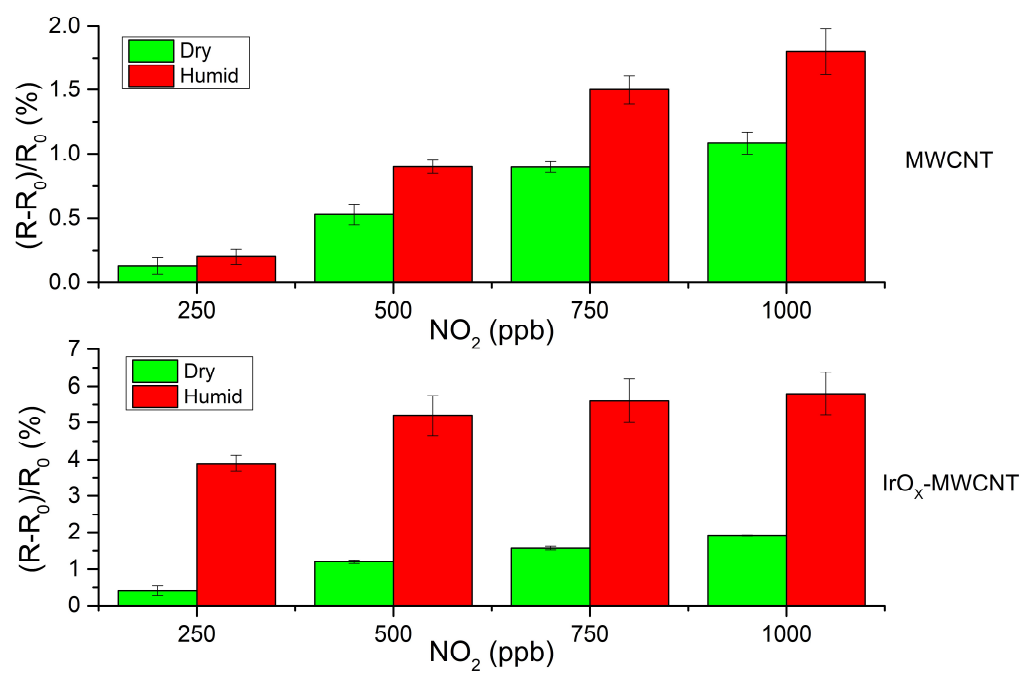

Figure 8. Comparison of the responses towards nitrogen dioxide of bare and $\mathrm{IrO}_{\mathrm{x}}$-decorated MWCNTs under dry and humid (50\% of relative humidity) conditions. Sensors were operated at $150{ }^{\circ} \mathrm{C}$. While for bare carbon nanotubes, the response under humid conditions shows an almost two-fold increase (in comparison to dry conditions), this increase in response is even higher for $\operatorname{IrO}_{\mathrm{x}}-\mathrm{MWCNTs}$ (nearly four-fold). 
The long term stability of the response towards nitrogen dioxide was studied as well. For this purpose, repeated nitrogen dioxide measurements were conducted at $1 \mathrm{ppm}$ under dry conditions for both $\mathrm{IrO}_{x}$ loaded and bare MWCNT sensors over a 6-month period. It was found that the response of $\mathrm{IrO}_{\mathrm{x}}-\mathrm{MWCNTs}$ was remarkably stable (variation was below 5\%). Figure S6 (Supplementary Materials) shows the details.

It is important to notice that $\mathrm{IrO}_{\mathrm{x}}-\mathrm{MWCNT}$ sensors are able to measure ppm and ppb levels of $\mathrm{NH}_{3}$ and $\mathrm{NO}_{2}$, respectively, with an excellent signal-to-noise ratio. For that reason, it is interesting to estimate the limit of detection (LOD) and limit of quantification (LOQ). In the case of ammonia, it was considered applying a linear regression to the calibration curve, following the method described by Shrivastava and co-workers [28]:

$$
\begin{aligned}
\mathrm{LOD} & =3 S_{a} / b \\
\mathrm{LOQ} & =10 S_{a} / b
\end{aligned}
$$

where $S_{a}$ was estimated by the standard deviation of y-intercepts and $b$ is the slope of the regression line obtained from Figure $4 \mathrm{~b}$. The theoretical LOD and LOQ for $\mathrm{IrO}_{\mathrm{x}}-\mathrm{MWCNTs}$ were estimated at hundreds of $\mathrm{ppb}$ for $\mathrm{NH}_{3}$ detection. These results should be confirmed with measurements at $\mathrm{ppb}$ range, however, these levels are much lower than the exposure limit [29] established by the Occupational Safety and Health Administration (OSHA), which is 50 ppm as an 8-h time-weighted average (TWA).

Carbon nanomaterials present high potential to detect very low concentrations of nitrogen dioxide. For that reason, $25 \mathrm{ppb}$ of $\mathrm{NO}_{2}$ were measured (see Figure 9) to check the ability of the sensors to reproducibly detect such a low concentration level. This is the lowest $\mathrm{NO}_{2}$ concentration that our measurement system is able to generate.

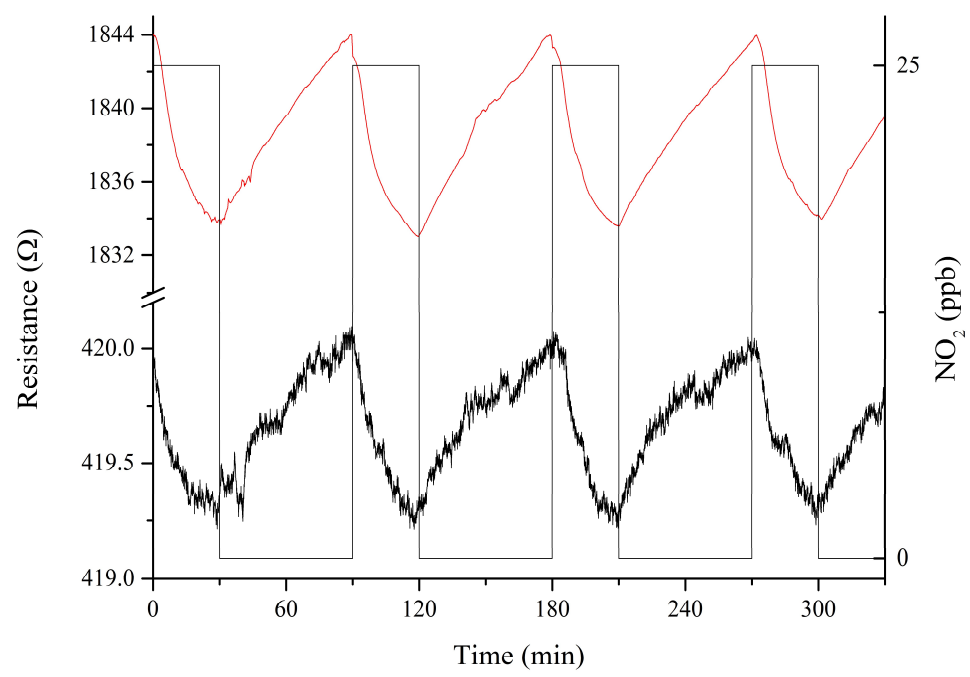

Figure 9. Example of the response for bare carbon nanotubes (black line) and $\mathrm{IrO}_{\mathrm{x}}-\mathrm{MWCNTs}$ (red line) to repeated pulses of nitrogen dioxide at $25 \mathrm{ppb}$. Sensors were operated at $150^{\circ} \mathrm{C}$. A baseline correction was implemented to suppress baseline drift.

To estimate the LOD and LOQ for nitrogen dioxide, a signal-to-noise method was employed [30]. The background noise level was calculated using 50 points during a stabilization step under a flow of dry air. In addition, for each sensor, the response signal for $25 \mathrm{ppb}$ of nitrogen dioxide was computed as the averaged response for 10 nitrogen dioxide pulses. This is illustrated for four pulses in Figure 9. Then, the sensitivity was estimated using the slope of the calibration curve shown in Figure $5 b$ (for the two lowest concentrations measured, i.e., 250 and $500 \mathrm{ppb}$ ) obtaining a sensitivity of $0.0032 \%$ $\mathrm{ppb}^{-1}$ and $0.0015 \% \mathrm{ppb}^{-1}$ for iridium oxide decorated and bare MWCNTs, respectively. Assuming a signal-to-noise ratio of 3 for LOD, and of 10 for LOQ, the estimated levels are summarized in 
Table 1. The lower values obtained with $\mathrm{IrO}_{\mathrm{x}}$ loaded MWCNTs are due to the higher response and signal-to-noise ratio for this hybrid nanomaterial than for bare MWCNTs.

Table 1. Estimated limits of detection and quantification for $\mathrm{NO}_{2}$. These theoretical levels should be confirmed with experimental measurements at this level of concentration.

\begin{tabular}{ccc}
\hline & CNT & IrOx-MWCNT \\
\hline LOD & $17.8 \mathrm{ppb}$ & $1 \mathrm{ppb}$ \\
LOQ & $59.1 \mathrm{ppb}$ & $3.2 \mathrm{ppb}$ \\
\hline
\end{tabular}

Maximum permitted exposure limits to $\mathrm{NO}_{2}$ are under continuous revision, but nowadays these are established at $200 \mathrm{ppb}$ and $100 \mathrm{ppb}$ (1-h exposure) by the European Union (EU) [31] and the US [32], respectively. Besides, the annual limit mean for primary and secondary exposure is $40 \mathrm{ppb}$ for the EU [31] and $53 \mathrm{ppb}$ for US [32]. Our sensors show clearly the possibility of detecting $25 \mathrm{ppb}$ of nitrogen dioxide and potential for detecting this toxic species even at lower levels. Nevertheless, real exposures to these concentrations of $\mathrm{NO}_{2}$ should be studied in order to confirm the theoretical LOD and LOQ obtained.

\section{Discussion}

Despite the fact that carbon nanotube mats can work at room temperature for gas sensing [33], the presence of metal oxide nanoparticles, which may show catalytic properties above room temperature, has encouraged us to explore the performance of the hybrid nanomaterials at moderate operating temperatures (up to $150{ }^{\circ} \mathrm{C}$ ). This should help us better apprehend the effect of $\mathrm{IrO}_{\mathrm{x}}$ nanoparticles decorating MWCNTs on gas sensing properties [34]. From the gas sensing tests, it was derived that the presence of $\mathrm{IrO}_{x} \mathrm{NPs}$ decorating the outer wall of MWCNTs was advantageous for detecting ammonia and nitrogen dioxide. Additionally, ammonia was better detected at an operating temperature of $100{ }^{\circ} \mathrm{C}$, while $150^{\circ} \mathrm{C}$ was better for detecting nitrogen dioxide. While MWCNTs offer oxygenated-defect sites and carboxylic acid functional groups to interact with these species, $\mathrm{IrO}_{x}$ nanoparticles present a high content of oxygen species on their surface, improving the sensitivity to some gases.

Ammonia is a reducing agent, acting as electron donor. Then, when p-type carbon nanotube mats interact with $\mathrm{NH}_{3}$, an increase in the film resistance is observed because electronic charge is transferred from adsorbed ammonia molecules towards CNTs [35]. The presence of oxygenated defects on the surface of CNTs favours their interaction with ammonia [36]. In contrast, nitrogen dioxide is a strong oxidizing agent with electrophilic properties, acting as electron acceptor. As a consequence, when nitrogen dioxide is adsorbed on carbon nanotubes, electronic charge is transferred from CNTs towards the adsorbed species and the electrical resistance of the mat decreases. As already discussed for ammonia, oxygenated defects can act as adsorption sites [37]. These mechanisms are detailed below:

$$
\begin{aligned}
& \mathrm{NH}_{3 \text { (gas) }} \rightarrow \mathrm{NH}_{3}{ }^{+} \text {(ads) }+\mathrm{e}^{-} \\
& \mathrm{NO}_{2} \text { (gas) }+\mathrm{e}^{-} \rightarrow \mathrm{NO}_{2}{ }^{-} \text {(ads) }
\end{aligned}
$$

At moderate temperatures, the adsorption barrier is further lowered by the presence of oxygen via adsorbed molecular oxygen from the environment and the oxygenated species and defects present on the carbon nanotube sidewalls [20]. These oxygenated species on MWCNTs can be attributed to the presence of functional groups resulting from the plasma treatment and adsorbed oxygen from the sensor environment during the experiments [38].

Moreover, independently of the operating temperature, decorated carbon nanotubes always show a higher response to ammonia or nitrogen dioxide than bare MWCNTs. The presence of $\operatorname{IrO}_{x}$ nanoparticles improves the response and sensitivity offered by carbon nanotubes. The interactions described between gases and oxygenated species for pristine carbon nanotubes can be applied to $\mathrm{IrO}_{x}$ nanoparticles as well. Nanoparticles of oxygen defective iridium oxide (as revealed by XPS) facilitate 
the interaction between gas molecules and adsorbed oxygen species $\left(\mathrm{O}_{2}{ }^{-}\right)$[36], which results in the transfer of electronic charge between adsorbed molecules and the NP-MWCNT system.

Nitrogen dioxide and ammonia can react with the oxygen species adsorbed at metal oxide nanoparticles, following the reactions proposed by Rahmani and co-workers [39]:

$$
\begin{gathered}
4 \mathrm{NH}_{3} \text { (gas) }+3 \mathrm{O}_{2}{ }^{-} \rightarrow 2 \mathrm{~N}_{2 \text { (gas) }}+6 \mathrm{H}_{2} \mathrm{O}+3 \mathrm{e}^{-} \\
\mathrm{NO}_{2 \text { (gas) }}+\mathrm{O}_{2}{ }^{-}+2 \mathrm{e}^{-} \rightarrow \mathrm{NO}_{2}{ }^{-} \text {(ads) }+2 \mathrm{O}^{-} \text {(ads) }
\end{gathered}
$$

The release (capture) of electrons upon adsorption of ammonia (nitrogen dioxide) results in the increase (decrease) of the electrical resistance of the $\mathrm{IrO}_{\mathrm{x}}-\mathrm{MWCNT}$ mats. In addition, iridium oxide has been reported as a catalytic material, and the XPS analysis conducted on iridium oxide decorated MWCNT samples (see Figure 3) has shown that two oxidation states coexist for Ir. The presence of both Ir (IV) and Ir (III) was determined, which means that NPs contain $\mathrm{IrO}_{2}$ and $\mathrm{Ir}_{2} \mathrm{O}_{3}$. The coexistence of these two iridium oxides could explain the high response towards ammonia and nitrogen dioxide obtained for $\mathrm{IrO}_{\mathrm{x}}$-decorated MWCNT samples in comparison to bare MWCNT samples. The gas sensing mechanism that we propose, derived from the occurrence of different oxidation states for iridium is detailed in Figure 10.

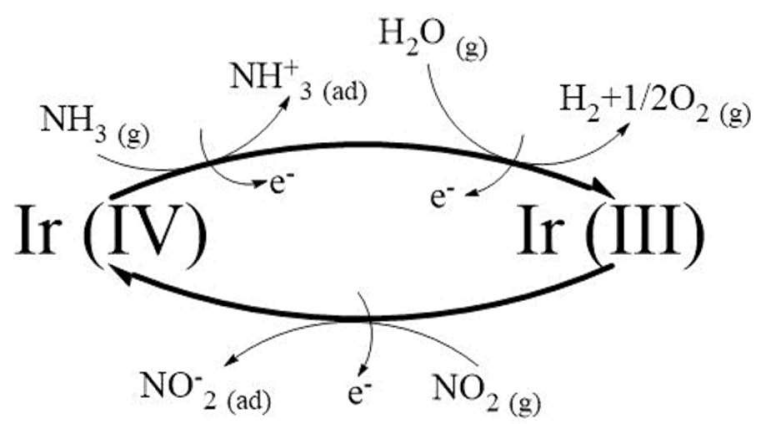

Figure 10. Gas sensing mechanism for iridium oxide nanoparticles decorating carbon nanotubes.

Probably iridium oxide nanoparticles present a redox interaction with the analytes, which means that Ir (IV) is reduced by $\mathrm{NH}_{3}$ going to Ir (III) state. However, $\mathrm{NO}_{2}$ can oxidize Ir (III) to Ir (IV). These interactions could explain the higher sensitivity to these gases observed for $\operatorname{IrO}_{\mathrm{x}}-\mathrm{MWCNTs}$. This is based on the presence of Ir (IV) and Ir (III) in the hybrid sensing material at the same time but in different ratios, depending on the gas tested.

We can consider now the presence of ambient moisture in the sensing mechanism. The high sensitivity of bare nanotubes to ambient moisture is well-known. In fact, carbon nanomaterials such as graphene and carbon nanotubes have been extensively reported as humidity sensors [40-42]. Here the enhancement in the response towards nitrogen dioxide or ammonia observed for bare MWCNT sensors under humid conditions can be attributed to a water mediated adsorption of gas molecules in semiconductor chemoresistors [43]. However, in $\mathrm{IrO}_{\mathrm{x}}$-decorated carbon nanotubes the interactions with humidity are more complex. First, $\mathrm{IrO}_{\mathrm{x}}-\mathrm{MWCNTs}$ show a similar response to ammonia under dry or humid conditions, even with ambient moisture the response is slightly lower. Probably the reason for this behaviour is related to the reducing properties of water (see Figure 10):

$$
\mathrm{H}_{2} \mathrm{O}_{(\text {gas })} \rightarrow 2 \mathrm{H}^{+} \text {(gas) }+1 / 2 \mathrm{O}_{2} \text { (gas) }+2 \mathrm{e}^{-}
$$

At $100{ }^{\circ} \mathrm{C}$, which was found optimal for detecting ammonia, $\mathrm{IrO}_{\mathrm{x}} \mathrm{NPs}$ are able to create a water splitting effect, reducing $\mathrm{Ir}$ (IV) to Ir (III). In consequence, reducing molecules such as $\mathrm{NH}_{3}$ and $\mathrm{H}_{2} \mathrm{O}$ are taking part in a competitive reaction that favours the reduction of $\mathrm{IrO}_{\mathrm{x}}$ towards $\mathrm{Ir}_{2} \mathrm{O}_{3}$, which would explain the similar response observed for ammonia under dry or humid conditions due to the limitation in the number of surface oxygen species to interact with. In contrast, $\operatorname{IrO}_{\mathrm{x}}-\mathrm{MWCNTs}$ 
show a higher response to $\mathrm{NO}_{2}$ in a humid environment than in dry air. Figure 10 can explain this behaviour because during any recovery phase under humid air, the occurrence of Ir (III) is favoured, increasing the Ir (III)/Ir (IV) ratio. This higher ratio explains the higher response recorded for a new $\mathrm{NO}_{2}$ exposure event.

Tables 2 and 3 summarize the performance achieved with previously reported metal or metal oxide decorated carbon nanotube materials in the detection of $\mathrm{NO}_{2}$ and $\mathrm{NH}_{3}$, respectively. In addition, these tables also help putting in context the results achieved using $\mathrm{IrO}_{\mathrm{x}}$-decorated carbon nanotubes. As described above, the operational sensitivity reported in these tables was estimated using the slope of the calibration curves for the lowest concentrations measured.

Table 2. Nitrogen dioxide sensitivities reported as $10^{-3} \% \mathrm{ppb}^{-1}$ for different metal or metal oxide nanoparticles decorating carbon nanotubes. TW $=$ This Work.

\begin{tabular}{ccc}
\hline CNT Decoration & Sensitivity & Reference \\
\hline $\mathrm{IrO}_{\mathrm{x}}$ & 3.2 & $\mathrm{TW}$ \\
$\mathrm{Au}$ & 8 & {$[44]$} \\
$\mathrm{Rh}$ & 5 & {$[37]$} \\
$\mathrm{Pt}$ & 0.094 & {$[45]$} \\
$\mathrm{Pd}$ & 0.069 & {$[45]$} \\
$\mathrm{SnO}_{2}$ & 4.8 & {$[46]$} \\
$\mathrm{ZnO}_{2}$ & 0.25 & {$[47]$} \\
\hline
\end{tabular}

Table 3. Ammonia sensitivities reported as $10^{-2} \% \mathrm{ppm}^{-1}$ for different metal nanoparticles decorating carbon nanotubes. TW $=$ This Work.

\begin{tabular}{ccc}
\hline CNT Decoration & Sensitivity & Reference \\
\hline $\mathrm{IrO}_{\mathrm{x}}$ & 1.71 & $\mathrm{TW}$ \\
$\mathrm{Co}$ & 0.36 & {$[48]$} \\
$\mathrm{Au}$ & 0.41 & {$[49]$} \\
$\mathrm{Pd}$ & 1.11 & {$[50]$} \\
$\mathrm{Pt}$ & 2.80 & {$[51]$} \\
$\mathrm{Ag}$ & 6.84 & {$[51]$} \\
\hline
\end{tabular}

\section{Conclusions}

A p-type chemoresistive sensor based on $\mathrm{IrO}_{x}$ nanoparticles decorating MWCNTs was devised to successfully detect harmful gases like $\mathrm{NO}_{2}$ and $\mathrm{NH}_{3}$ at different working temperatures. These loaded carbon nanotubes show enhanced gas sensing properties, such as better reproducibility, higher sensitivity, stability, and lower noise levels in comparison to their bare MWCNT counterparts. In addition, the effect of relative humidity on sensor response was studied, and a detailed gas sensing mechanism was proposed to understand the influence of ambient moisture in the presence of a catalytic nanomaterial like iridium oxide nanoparticles. Finally, low level of cross-sensitivity was observed for a range of different gases and vapors with interfering potential. In consequence, $\mathrm{IrO}_{\mathrm{x}}-\mathrm{MWCNT}$ nanomaterial enables quite a selective detection of nitrogen dioxide or ammonia against other hazardous gases, with low detection limits, making it a potential nanomaterial to be employed in real applications.

Supplementary Materials: The following are available online at http:/ /www.mdpi.com/1424-8220/19/1/113/s1. Figure S1: summary of $\mathrm{IrO}_{\mathrm{x}} \mathrm{NPs}$ synthesis, Figure S2: Gas testing chamber and design of sensor used, Figure S3: TEM-EDXS spectrum of the $\mathrm{IrO}_{\mathrm{x}}-\mathrm{MWCNT}$ sample, Figure S4: Acetaldehyde detection, Figure S5: Response to $\mathrm{NO}_{2}$ in humid conditions for $\mathrm{IrO}_{\mathrm{x}}-\mathrm{MWCNTs}$, Table S1: Average responses and associated standard deviations, Figure S6: Response stability test.

Author Contributions: J.C.-C. synthesized the nanoparticles, performed the experiments and contributed to the discussion and the writing. E.N. assisted to the nanoparticle synthesis. X.N. and C.B. performed and interpreted the SEM and XPS analysis. P.U. performed and interpreted HR-TEM and EDXS analysis. E.L. supervised the work and contributed to the discussion of results. 
Funding: This research was funded by MINECO and FEDER under grant no. TEC2015-71663-R, AGAUR under grant no. 2017 SGR 418. The project FITTED-FNRS (J 0230.17) is also acknowledged. C.B. and P.U. gratefully acknowledge the financial support provided by COST action CA15107. J.C.-C. is supported by a Martí $i$ Franquès pre-doctoral fellowship from Universitat Rovira i Virgili (URV), E.L. is supported by the Catalan Institution for Research and Advanced Studies via the ICREA Academia Award. C.B. is a researcher associate at the FRS-FNRS.

Acknowledgments: We are thankful to Moncusí for the help provided with Raman experiments.

Conflicts of Interest: The authors declare no conflict of interest.

\section{References}

1. Llobet, E. Gas sensors using carbon nanomaterials: A review. Sens. Actuators B Chem. 2013, 179, $32-45$. [CrossRef]

2. Holzinger, M.; Vostrowsky, O.; Hirsch, A.; Hennrich, F.; Kappes, M.; Weiss, R.; Jellen, F. Sidewall Functionalization of Carbon Nanotubes. Angew. Chem. Int. Ed. 2001, 40, 4002-4005. [CrossRef]

3. Zhang, Z.; Pfefferle, L.; Haller, G.L. Characterization of functional groups on oxidized multi-wall carbon nanotubes by potentiometric titration. Catal. Today 2015, 249, 23-29. [CrossRef]

4. Kharisov, B.I.; Kharissova, O.V.; Ortiz Méndez, U.; De La Fuente, I.G. Decoration of Carbon Nanotubes with Metal Nanoparticles: Recent Trends. Synth. React. Inorg. Met. Nano Met. Chem. 2016, 46, 55-76. [CrossRef]

5. Irfan, M.; Pham, X.-H.; Han, K.N.; Li, C.A.; Hong, M.H.; Seong, G.H. Decoration of carbon nanotube films with iridium nanoparticles and their electrochemical characterization. BioChip J. 2014, 8, 129-136. [CrossRef]

6. Blakemore, J.D.; Crabtree, R.H.; Brudvig, G.W. Molecular Catalysts for Water Oxidation. Chem. Rev. 2015, 115, 12974-13005. [CrossRef] [PubMed]

7. Wilson, M.S.; Rauh, R.D. Novel amperometric immunosensors based on iridium oxide matrices. Biosens. Bioelectron. 2004, 19, 693-699. [CrossRef]

8. Irhayem, E.A.; Elzanowska, H.; Jhas, A.S.; Skrzynecka, B.; Birss, V. Glucose detection based on electrochemically formed Ir oxide films. J. Electroanal. Chem. 2002, 538-539, 153-164. [CrossRef]

9. Marzouk, S.A.M.; Ufer, S.; Buck, R.P.; Johnson, T.A.; Dunlap, L.A.; Cascio, W.E. Electrodeposited iridium oxide $\mathrm{pH}$ electrode for measurement of extracellular myocardial acidosis during Acute Ischemia. Anal. Chem. 1998, 70, 5054-5061. [CrossRef]

10. Huang, W.D.; Cao, H.; Deb, S.; Chiao, M.; Chiao, J.C. A flexible pH sensor based on the iridium oxide sensing film. Sens. Actuators A Phys. 2011, 169,1-11. [CrossRef]

11. Brewer, S.H.; Wicaksana, D.; Maria, J.P.; Kingon, A.I.; Franzen, S. Investigation of the electrical and optical properties of iridium oxide by reflectance FTIR spectroscopy and density functional theory calculations. Chem. Phys. 2005, 313, 25-31. [CrossRef]

12. Lang, A.C.; Fleischer, M.; Meixner, H. Surface modifications of $\mathrm{Ga}_{2} \mathrm{O}_{3}$ thin film sensors with $\mathrm{Rh}, \mathrm{Ru}$ and $\mathrm{Ir}$ clusters. Sens. Actuators B Chem. 2000, 66, 80-84. [CrossRef]

13. Bastuck, M.; Puglisi, D.; Huotari, J.; Sauerwald, T.; Lappalainen, J.; Lloyd Spetz, A.; Andersson, M.; Schütze, A. Exploring the selectivity of $\mathrm{WO}_{3}$ with iridium catalyst in an ethanol/naphthalene mixture using multivariate statistics. Thin Solid Films 2016, 618, 263-270. [CrossRef]

14. Castañeda, L.; Maldonado, A.; Olvera, M.L. Sensing properties of chemically sprayed $\mathrm{TiO}_{2}$ thin films using $\mathrm{Ni}$, Ir, and Rh as catalysts. Sens. Actuators B Chem. 2008, 133, 687-693. [CrossRef]

15. Ozaki, Y.; Suzuki, S.; Morimitsu, M.; Matsunaga, M. Temperature and humidity dependence of $\mathrm{SnO}_{2}$-based CO gas sensors modified with iridium and ruthenium. Electrochem. Solid State Lett. 2000, 3, 297-299. [CrossRef]

16. Pisal, S.H.; Harale, N.S.; Bhat, T.S.; Dshmukh, H.P.; Patil, P.S. Functionalized Multi-Walled Carbon Nanotubes for Nitrogen Sensor. IOSR J. Appl. Chem. 2014, 7, 49-52. [CrossRef]

17. Peng, N.; Zhang, Q.; Chow, C.L.; Tan, O.K.; Marzari, N. Sensing Mechanisms for Carbon Nanotube Based $\mathrm{NH}_{3}$ Gas Detection. Nano Lett. 2009, 9, 1626-1630. [CrossRef]

18. Karthigeyan, A.; Gupta, R.P.; Scharnagl, K.; Burgmair, M.; Sharma, S.K.; Eisele, I. A room temperature HSGFET ammonia sensor based on iridium oxide thin filmsmall size electronic nose. Sens. Actuators B Chem. 2002, 85, 145-153. [CrossRef] 
19. Zhao, Y.; Hernandez-Pagan, E.A.; Vargas-Barbosa, N.M.; Dysart, J.L.; Mallouk, T.E. A high yield synthesis of ligand-free iridium oxide nanoparticles with high electrocatalytic activity. J. Phys. Chem. Lett. 2011, 2, 402-406. [CrossRef]

20. Dresselhaus, M.S.; Jorio, A.; Hofmann, M.; Dresselhaus, G.; Saito, R. Perspectives on carbon nanotubes and graphene Raman spectroscopy. Nano Lett. 2010, 10, 751-758. [CrossRef]

21. Korotcov, A.V.; Huang, Y.-S.; Tiong, K.-K.; Tsai, D.-S. Raman scattering characterization of well-aligned $\mathrm{RuO}_{2}$ and $\mathrm{IrO}_{2}$ nanocrystals. J. Raman Spectrosc. 2007, 38, 1538-1553. [CrossRef]

22. D'Acunto, G.; Ripanti, F.; Postorino, P.; Betti, M.G.; Scardamaglia, M.; Bittencourt, C.; Mariani, C. Channelling and induced defects at ion-bombarded aligned multiwall carbon nanotubes. Carbon 2018, 139, 768-775. [CrossRef]

23. Bittencourt, C.; Felten, A.; Douhard, B.; Ghijsen, J.; Johnson, R.L.; Drube, W.; Pireaux, J.-J. Photoemission studies of gold clusters thermally evaporated on multiwall carbon nanotubes. Chem. Phys. 2006, 328, 385-391. [CrossRef]

24. Chen, C.; Liang, B.; Ogino, A.; Wang, X.; Nagatsu, M. Oxygen Functionalization of Multiwall Carbon Nanotubes by Microwave-Excited Surface-Wave Plasma Treatment. J. Phys. Chem. C 2009, 113, 7659-7665. [CrossRef]

25. Casella, I.G.; Contursi, M.; Toniolo, R. Anodic electrodeposition of iridium oxide particles on glassy carbon surfaces and their electrochemical/SEM/XPS characterization. J. Electroanal. Chem. 2015, 736, 147-152. [CrossRef]

26. Kötz, R.; Neff, H.; Stucki, S. Anodic Iridium Oxide Films. J. Electrochem. Soc. 1984, 131, 72. [CrossRef]

27. Liu, L.; Ye, X.; Wu, K.; Han, R.; Zhou, Z.; Cui, T. Humidity Sensitivity of Multi-Walled Carbon Nanotube Networks Deposited by Dielectrophoresis. Sensors 2009, 9, 1714-1721. [CrossRef]

28. Shrivastava, A.; Gupta, V.B. Methods for the determination of limit of detection and limit of quantitation of the analytical methods. Chronicles Young Sci. 2011, 2, 21-25. [CrossRef]

29. Ammonia. Available online: https://www.cdc.gov/niosh/pel88/7664-41.html (accessed on 7 August 2018).

30. Forootan, A.; Sjöback, R.; Björkman, J.; Sjögreen, B.; Linz, L.; Kubista, M. Methods to determine limit of detection and limit of quantification in quantitative real-time PCR (qPCR). Biomol. Detect. Quantif. 2017, 12, 1-6. [CrossRef]

31. Air Quality Standards. Available online: http://ec.europa.eu/environment/air/quality/standards.htm (accessed on 7 August 2018).

32. NAAQS Table. Available online: https://www.epa.gov/criteria-air-pollutants/naaqs-table (accessed on 7 August 2018).

33. Tang, R.; Shi, Y.; Hou, Z.; Wei, L. Carbon nanotube-based chemiresistive sensors. Sensors 2017, $17,882$. [CrossRef]

34. Wang, C.; Yin, L.; Zhang, L.; Xiang, D.; Gao, R. Metal oxide gas sensors: Sensitivity and influencing factors. Sensors 2010, 10, 2088-2106. [CrossRef] [PubMed]

35. Shankar, P.; Bosco, J.; Rayappan, B. Gas sensing mechanism of metal oxides: The role of ambient atmosphere, type of semiconductor and gases-A review. Sci. Lett. J. 2015, 4, 126.

36. Rout, C.S.; Hegde, M.; Govindaraj, A.; Rao, C.N.R. Ammonia sensors based on metal oxide nanostructures. Nanotechnology 2007, 18, 205504. [CrossRef]

37. Leghrib, R.; Dufour, T.; Demoisson, F.; Claessens, N.; Reniers, F.; Llobet, E. Gas sensing properties of multiwall carbon nanotubes decorated with rhodium nanoparticles. Sens. Actuators B Chem. 2011, 160, 974-980. [CrossRef]

38. Sayago, I.; Santos, H.; Horrillo, M.C.; Aleixandre, M.; Fernández, M.J.; Terrado, E.; Tacchini, I.; Aroz, R.; Maser, W.K.; Benito, A.M.; et al. Carbon nanotube networks as gas sensors for $\mathrm{NO}_{2}$ detection. Talanta 2008, 77, 758-764. [CrossRef]

39. Rahmani, M.B.; Breedon, M.; Lau, D.; Campbell, J.L.; Moafi, A.; McCulloch, D.G.; Wlodarski, W.; Kalantar-Zadeh, K. Gas sensing properties of interconnected ZnO nanowires. Sens. Lett. 2011, 9, 1-7. [CrossRef]

40. Han, J.W.; Kim, B.; Li, J.; Meyyappan, M. Carbon nanotube based humidity sensor on cellulose paper. J. Phys. Chem. C 2012, 116, 22094-22097. [CrossRef]

41. Chen, W.-P.; Zhao, Z.-G.; Liu, X.-W.; Zhang, Z.-X.; Suo, C.-G. A Capacitive Humidity Sensor Based on Multi-Wall Carbon Nanotubes (MWCNTs). Sensors 2009, 9, 7431-7444. [CrossRef] 
42. Zhao, Z.G.; Liu, X.W.; Chen, W.P.; Li, T. Carbon nanotubes humidity sensor based on high testing frequencies. Sens. Actuators A Phys. 2011, 168, 10-13. [CrossRef]

43. Roso, S.; Degler, D.; Llobet, E.; Barsan, N.; Urakawa, A. Temperature-Dependent $\mathrm{NO}_{2}$ Sensing Mechanisms over Indium Oxide. ACS Sens. 2017, 2, 1272-1277. [CrossRef]

44. Mudimela, P.R.; Scardamaglia, M.; González-León, O.; Reckinger, N.; Snyders, R.; Llobet, E.; Bittencourt, C.; Colomer, J.F. Gas sensing with gold-decorated vertically aligned carbon nanotubes. Beilstein J. Nanotechnol. 2014, 5, 910-918. [CrossRef] [PubMed]

45. Baccar, H.; Thamri, A.; Clément, P.; Llobet, E.; Abdelghani, A. Pt- and Pd-decorated MWCNTs for vapour and gas detection at room temperature. Beilstein J. Nanotechnol. 2015, 6, 919-927. [CrossRef] [PubMed]

46. Leghrib, R.; Llobet, E.; Pavelko, R.; Vasiliev, A.A.; Felten, A.; Pireaux, J.J. Gas sensing properties of MWCNTs decorated with gold or tin oxide nanoparticles. Procedia Chem. 2009, 1, 168-171. [CrossRef]

47. Kwon, Y.J.; Mirzaei, A.; Kang, S.Y.; Choi, M.S.; Bang, J.H.; Kim, S.S.; Kim, H.W. Synthesis, characterization and gas sensing properties of ZnO-decorated MWCNTs. Appl. Surf. Sci. 2017, 413, 242-252. [CrossRef]

48. Nguyen, L.Q.; Phan, P.Q.; Duong, H.N.; Nguyen, C.D.; Nguyen, L.H. Enhancement of $\mathrm{NH}_{3}$ gas sensitivity at room temperature by carbon nanotube-based sensor coated with Co nanoparticles. Sensors 2013, 13, 1754-1762. [CrossRef] [PubMed]

49. Young, S.J.; Lin, Z.D. Ammonia gas sensors with Au-decorated carbon nanotubes. Microsyst. Technol. 2018, 24, 4207-4210. [CrossRef]

50. Choi, H.H.; Lee, J.; Dong, K.Y.; Ju, B.K.; Lee, W. Noxious gas detection using carbon nanotubes with Pd nanoparticles. Nanoscale Res. Lett. 2011, 6, 1-6. [CrossRef]

51. Lich, N.Q.; Thanh, T.P.; Truong, D.V.; Kien, P.T.; Tu, N.C.; Bac, L.H.; Vuong, D.D.; Chien, N.D.; Lam, N.H. Pt- and Ag-Decorated Carbon Nanotube Network Layers for Enhanced $\mathrm{NH}_{3}$ Gas Sensitivity at Room Temperature. Mater. Trans. 2015, 56, 1399-1402. [CrossRef]

(C) 2018 by the authors. Licensee MDPI, Basel, Switzerland. This article is an open access article distributed under the terms and conditions of the Creative Commons Attribution (CC BY) license (http://creativecommons.org/licenses/by/4.0/). 